\title{
The prevalence of COPD co-morbidities in Serbia: results of a national survey
}

\author{
Ljudmila M Nagorni-Obradovic ${ }^{1,2}$ and Dejana S Vukovic ${ }^{3}$
}

BACKGROUND: Research studies have found different prevalence rates for co-morbidities in patients with chronic obstructive pulmonary disease (COPD).

AIMS: The aim of our study was to investigate the prevalence of co-morbidities as well as functional limitations in subjects with COPD.

METHODS: The study was based on a nationally representative sample of the population of Serbia. Information on the health of the population was obtained from interviews and anthropometric measurements. In this study we analysed a total of 10,013 respondents aged 40 years or older. There were 653 subjects with COPD and 9,360 respondents without COPD.

RESULTS: Out of the 10,013 respondents, 5,377 were aged 40-59 years and 4,636 were 60 years or older. The prevalence of COPD was $5.0 \%$ in respondents aged $40-59$ years and $8.3 \%$ in those aged 60 years or older; the total prevalence was $6.5 \%$. The most prevalent co-morbidities among respondents with COPD were hypertension (54.5\%) and dyslipidaemia (26.5\%). The prevalence of all analysed co-morbidities was higher in respondents with COPD and the difference was highly statistically significant, except for stroke and malignancies, for which the difference was significant. Analysis showed that respondents with COPD had a higher prevalence of all analysed clinical factors (dizziness, obesity, anaemia and frailty) and functional impairments (mobility and hearing and visual impairment) compared with respondents without COPD. For those aged 40-59 years the difference was highest for mobility difficulty (four times higher prevalence in COPD patients) and anaemia (three times higher in COPD patients).

CONCLUSION: Our analysis showed that the most prevalent co-morbidities in COPD were hypertension, dyslipidaemia, chronic renal disease and anxiety/depression. The finding suggests that health professionals should actively assess co-morbidities in patients with COPD.

npj Primary Care Respiratory Medicine (2014) 24, Article number: 14008; doi:10.1038/npjpcrm.2014.8; published online 12 June 2014

\section{INTRODUCTION}

During the last decade of the 20th century, the health status of the Serbian population was negatively affected by numerous factors such as long-lasting economic crisis, war in the surrounding countries and Serbia, and economic and diplomatic sanctions. However, in the last several years, Serbia has faced economic growth; in 2006, the gross domestic product per capita amounted to $€ 3,354$, with $5.7 \%$ growth. Also, Serbia's literacy rate of $99.4 \%$ in the population aged 15-24 years is similar to that of other southeast European countries. The Gini index in 2006 was 28, which is not far from that of the neighbouring countries, with Bosnia and Herzegovina and Slovenia having slightly lower (27 and 26, respectively) and Macedonia, Bulgaria and Croatia slightly higher $\left(29,33\right.$ and 36 , respectively) values. ${ }^{1}$ The total expenditure on health in 2006 was $8.1 \%$ of the gross domestic product. $^{2}$

Compared with most former socialist countries, Serbia's transition has started with a delay. The isolation and policy stagnation in the 1990s left it somewhat behind the other transition states in terms of socioeconomic development. In 2009 the income ratio between the most affluent and the least affluent regions was $\sim 1: 4(€ 143: 524) .^{3}$

In chronic obstructive pulmonary disease (COPD), co-morbid conditions or co-morbidities may be defined as other serious diseases and chronic medical conditions that affect individuals who have COPD. ${ }^{4}$ Research studies have found different prevalence rates for co-morbidities in patients with COPD., ${ }^{4,5} \mathrm{Co}$ morbid illnesses are very important in COPD for multiple reasons: shared pathophysiological mechanisms for COPD and other chronic diseases and co-morbid illnesses may have a significant impact on the health status and utilisation of health services as well as hospitalisation of patients with COPD, and co-morbid illnesses, such as ischaemic heart disease or malignancies, could cause mortality earlier than respiratory causes. Aryal et al. ${ }^{5}$ also pointed out that understanding clusters of co-morbid illnesses could be important for better understanding the diagnosis, therapy and prognosis of COPD. However, Schnell et al. ${ }^{6}$ pointed out that studies on co-morbidities in COPD have typically focussed on select medical conditions such as heart failure and diabetes mellitus. These studies have largely failed to look comprehensively at many other high-priority conditions and functional limitations such as cognitive impairment and limited mobility. Functional limitations can have an important impact on the treatment of chronic conditions, and these conditions may also modify the effectiveness of COPD therapy, cause dangerous therapeutic interactions and make COPD therapies less feasible. ${ }^{6}$

The aim of our study was to investigate the prevalence of clinically relevant co-morbidities as well as functional limitations in subjects with COPD, and to explore whether the presence of

${ }^{1}$ Faculty of Medicine, University of Belgrade, Belgrade, Serbia; ${ }^{2}$ Clinic for Pulmonology, Clinical Centre of Serbia, Belgrade, Serbia and ${ }^{3}$ Faculty of Medicine, Institute of Social Medicine, Centre School of Public Health, University of Belgrade, Belgrade, Serbia.

Correspondence: DS Vukovic (dvukovic@med.bg.ac.rs)

Received 25 September 2013; revised 3 March 2014; accepted 16 March 2014 
co-morbidities and functional limitations differ according to age and smoking status.

\section{MATERIALS AND METHODS}

\section{Study population}

The Institute of Public Health conducted a multipurpose health survey of the population of Serbia (excluding Kosovo) in 2006. A stratified two-stage randomised sample of all registered households in Serbia was used. The sample was selected to provide statistically reliable estimates of health at

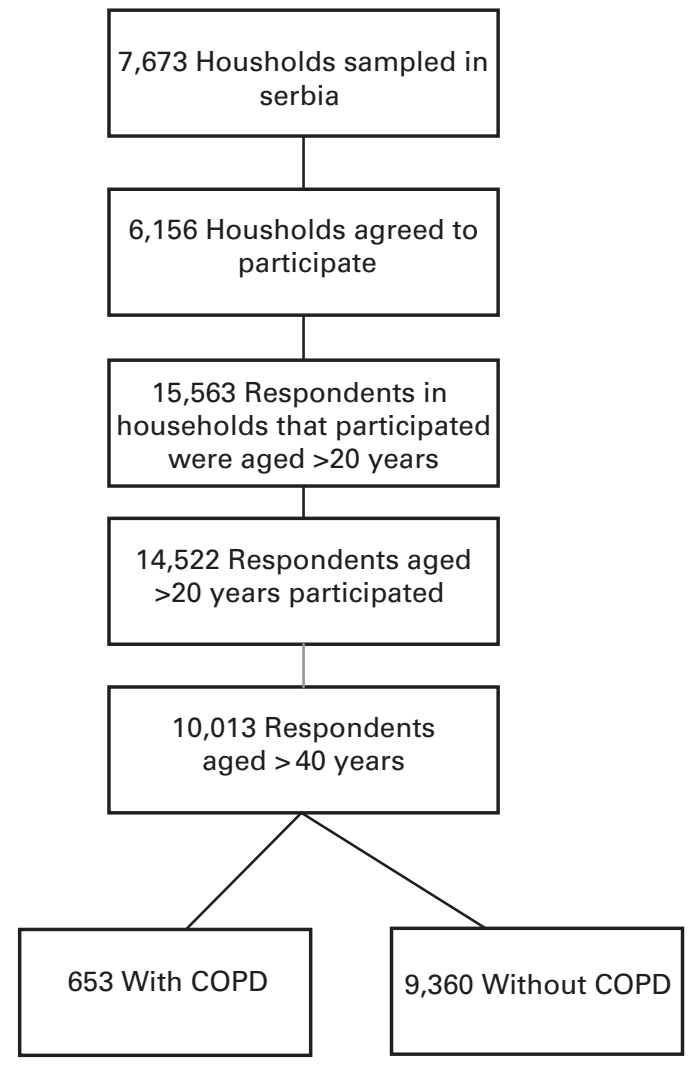

Figure 1. Selection of respondents. the national level and the sample was representative for the population of Serbia as a whole, as well as for urban and rural areas and for males and females. Information on the health of the population was obtained from interviews and anthropometric and blood pressure measurements. Interviews were performed in households of the respondents by a team consisting of one trained interviewer and a health worker who recorded anthropometric and blood pressure measurements. Out of 7,673 households selected, 6,156 were interviewed. The household response rate was $86.5 \%$. In the households, there were 15,563 adults aged $\geqslant 20$ years, of whom 14,522 were interviewed, yielding a response rate of $93.3 \%$. The overall response rate for adults was $80.5 \%$. All adults aged 20 years and above were included, except those living in institutions (Figure 1).

All respondents were informed about the purpose of the investigation and agreed to participate. The Review Board of the Ministry of Health of Serbia and the Institute of Public Health of Serbia approved the study.

In this study we analysed a total of 10,013 respondents aged 40 years or older.

Taking into account the complexity of sampling, we included weightage in the analysis to maintain population representativeness. Weightages were calculated on the basis of estimated data for the population of Serbia in 2006.

\section{Variables}

The classification variable to identify respondents with COPD was a selfreported history of chronic bronchitis and emphysema as measured by the following question: 'Has a doctor ever diagnosed you to have chronic bronchitis or emphysema?' Participants who answered positively were considered to have COPD. There were 653 subjects with COPD and 9,360 respondents without COPD, and they were analysed for the prevalence of other chronic diseases and functional limitations. The presence of other chronic diseases was measured by the following question: 'Has a doctor ever diagnosed you to have following diseases?' Respondents were asked to indicate all diseases diagnosed. We analysed the presence of heart attack, hypertension, stroke, asthma, malignancies, diabetes mellitus, dyslipidaemia, anxiety or depression, chronic renal disease, peptic ulcer and osteoporosis. As other clinical factors we included obesity, anaemia, frailty and dizziness.

Weight and height were measured by trained health workers following a defined protocol. Body mass index (BMI) was calculated on the basis of these values. Respondents were categorised as obese if BMI was above 30. Presence of anaemia was self-reported.

Respondents were defined as 'frail' if they had at least three of the following characteristics: ${ }^{6}$ low BMI, weakness, exhaustion and low physical activity. BMI $\leqslant 18.5$ was defined as low BMI. Weakness was defined using the following question: 'Are you able to lift and carry 5 kilos?' If the answer was 'I am not able', 'with some difficulties' or 'with much difficulties', respondents were classified as weak. Exhaustion was defined using the question 'What is the longest distance that you can walk without stopping

Table 1. Socio-demographic characteristics of respondents

\begin{tabular}{|c|c|c|c|c|c|c|c|c|c|}
\hline \multirow[t]{3}{*}{ Parameters } & \multicolumn{3}{|c|}{ Total subjects } & \multicolumn{6}{|c|}{ Age } \\
\hline & \multirow[b]{2}{*}{ Non-COPD } & \multirow[b]{2}{*}{$C O P D$} & \multirow[b]{2}{*}{$\mathrm{P}$} & \multicolumn{3}{|c|}{$40-59$ years } & \multicolumn{3}{|c|}{$60+$ years } \\
\hline & & & & Non-COPD & $C O P D$ & $\mathrm{P}$ & Non-COPD & $C O P D$ & $\mathrm{P}$ \\
\hline Gender (male) & 4,901 (54.4\%) & $285(46.6 \%)$ & $<0.01$ & 2,562 (51.4\%) & $110(42.5 \%)$ & $<0.01$ & $2,339(58.1 \%)$ & 175 (49.7\%) & $<0.01$ \\
\hline Mean age (s.d.), years & $59.3(12.2)$ & $62.8(12.4)$ & $<0.01$ & $49.8(5.7)$ & $50.4(5.7)$ & 0.69 & $71.0(6.9)$ & $72.0(6.6)$ & $<0.01$ \\
\hline Secondary & $3,588(38.3 \%)$ & $220(33.7 \%)$ & & $2,658(52.0 \%)$ & $138(51.3 \%)$ & & 930 (21.9\%) & $82(21.4 \%)$ & \\
\hline University & $1,188(12.7 \%)$ & $62(9.5 \%)$ & & 795 (15.6\%) & $26(9.7 \%)$ & & $393(9.2 \%)$ & 36 (9.4\%) & \\
\hline Smoking & & & $<0.01$ & & & $<0.01$ & & & $<0.01$ \\
\hline Never-smoker & $3,797(40.6 \%)$ & 206 (31.5\%) & & 1,992 (39.0\%) & 78 (29.0\%) & & $1,805(42.4 \%)$ & $128(33.3 \%)$ & \\
\hline Ex-smokers & 1,222 (13.0\%) & $110(16.8 \%)$ & & 649 (12.7\%) & $47(17.5 \%)$ & & 573 (13.5\%) & $63(16.4 \%)$ & \\
\hline Current smokers & $2,486(26.6 \%)$ & $171(26.2 \%)$ & & 1,989 (38.9\%) & $117(43.5 \%)$ & & 497 (11.7\%) & $54(14.1 \%)$ & \\
\hline Unknown & 1,855 (19.8\%) & $166(25.4 \%)$ & & 478 (9.4\%) & 27 (10.0\%) & & 1,377 (32.4\%) & $139(36.2 \%)$ & \\
\hline
\end{tabular}


or feeling very tired?' If the answer was 'not at all' or 'only few steps', respondents were defined as exhausted. Respondents were classified as having low physical activity if they estimated their physical activity as very bad or bad on a five-point scale.

Respondents were counted as having dizziness if they reported having dizziness in the previous 4 weeks.

We analysed functional limitations: hearing and visual impairment and mobility difficulty. Hearing impairment was defined as having trouble hearing when having a conversation with another person.

Visual impairment was defined as having extreme difficulty when reading text in newspapers or not able to read at all.

Mobility difficulty was defined as experiencing difficulty to walk $500 \mathrm{~m}$. The smoking status was classified as never-smokers (never smoked daily), ex-smokers (ceased smoking $\geqslant 1$ year earlier) and current daily smokers.

\section{Statistical analysis}

The distribution of subjects with and without COPD according to sociodemographic characteristics (gender, age and education) and smoking status was analysed using descriptive statistics, the chi-square test and the t-test.

Differences in the prevalence of co-morbidities, clinical factors and health status factors between subjects with and without COPD were analysed using the chi-square test. Analyses were performed separately for age groups $40-59$ years and above 60 years; for males and females; as well as for never-smokers, ex-smokers and current smokers.

Logistic regression analysis was performed to analyse the likelihood of occurrence of co-morbid illnesses, clinical factors and health status factors for respondents with and without COPD, adjusted for age, gender, educational level and smoking status. Tests were considered significant if $P<0.05$.

\section{RESULTS}

Participants

In our study, out of 10,013 respondents 5,377 were in the age group of 40-59 years and 4,636 were aged 60 and above. The prevalence of COPD has been estimated to be $5.0 \%$ in those aged $40-59$ years and $8.3 \%$ in those aged 60 and above, and the total prevalence was $6.5 \%$. Among respondents with COPD 26.2\% were current smokers and $16.8 \%$ were ex-smokers, and among those without COPD $26.6 \%$ were current smokers and $13.0 \%$ were exsmokers, and the difference was statistically significant. The prevalence of smoking was significantly higher among those with COPD in both the age groups (Table 1)

\section{Prevalence of co-morbidities}

Table 2 shows the prevalence of different co-morbid diseases among respondents with and without COPD.

The most prevalent co-morbidities among respondents with COPD were hypertension and dyslipidaemia.

The prevalence of all analysed co-morbidities was higher in respondents with COPD and the difference was statistically significant except for malignancies. When analysed separately in the two age groups, the prevalence of stroke and malignancies was not significantly different between respondents with and without COPD. Although the prevalence of heart attack was higher among respondents with COPD in the older age group, the difference was not significant.

When prevalence of co-morbidities was analysed separately for females and males, the prevalence of malignancies was not significantly different in respondents with and without COPD in both females and males. On the other hand, the prevalence of stroke was significantly higher only in male respondents with COPD. Peptic ulcer and heart attack were significantly more prevalent in female respondents with COPD. All other co-morbid illnesses were significantly more prevalent in both males and females with COPD. When co-morbidities were analysed separately for never-smokers, ex-smokers and current smokers, results

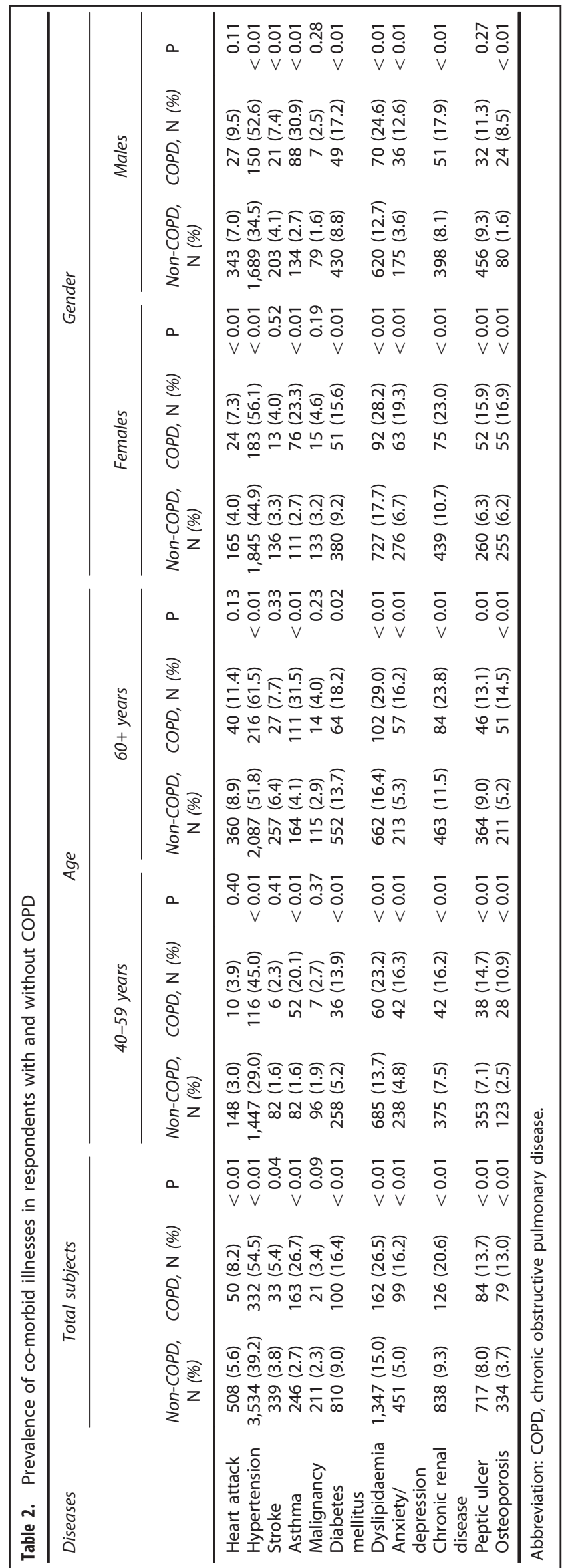


showed that among never-smokers osteoporosis and anxiety/ depression were three times more prevalent in respondents with COPD compared with those without COPD. In current smokers, osteoporosis was seven times more prevalent in respondents with COPD. Diabetes mellitus and chronic renal disease were two times more prevalent in respondents with COPD compared with those without COPD in both never-smokers and current smokers.

Among never-smokers the prevalence of stroke was not significantly different between respondents with and without COPD, but among ex-smokers stroke was more than two times more prevalent in respondents with COPD. Interestingly, in current smokers the difference was not significant (Table 3 ).

Prevalence of clinical and health status factors

Analysis of clinical factors and health status factors showed that respondents with COPD had a higher prevalence of all analysed clinical factors and functional impairments compared with respondents without COPD (Table 4). For the age group 40-59 years, the difference in prevalence was highest for mobility difficulty (four times higher prevalence among respondents with COPD) and anaemia (three times higher prevalence in respondents with COPD). The prevalence of frailty was not significantly different in the age group of 40-59 years between respondents with and without COPD.

In the age group of 60 years and older, the prevalence of anaemia was more than two times higher in respondents with COPD. All other clinical and health status factors were more prevalent in respondents with COPD, except obesity.

When clinical and health status factors were analysed separately for females and males, it was seen that in females the prevalence of frailty was significantly higher among those with COPD, but among males the difference was not significant. Mobility difficulty and hearing and visual impairment were significantly higher in both females and males with COPD (Table 4).

In never-smokers, the prevalence of all analysed health status and clinical factors was higher in respondents with COPD and the difference was statistically significant. In respondents who have smoked, the prevalence of most of the analysed health status and clinical factors was significantly higher in respondents with COPD, except obesity. The prevalence of dizziness, mobility difficulty and hearing and visual impairment was almost three times higher in current smokers with COPD compared with ex-smokers, in whom it was two times higher. In current smokers with COPD, the prevalence of anaemia was five times higher than in those without
COPD. In ex-smokers this difference was threefold. However, the prevalence of obesity was not significantly different between exsmokers and current smokers with and without COPD. Among current smokers, frailty was significantly higher in subjects with COPD (Table 5).

Logistic regression models of co-morbid illnesses and clinical and health status factors

In Table 6 results of the logistic regression analysis are presented. We analysed the odds ratios for different co-morbidities for respondents with COPD compared with those without COPD when controlling for age, gender, education and smoking status. Respondents with COPD had an almost 12 times higher likelihood of being diagnosed with asthma and 3.5 times higher likelihood of being diagnosed with anxiety/depression and osteoporosis compared with those without COPD. For osteoporosis, we additionally analysed a model that included physical activity and $\mathrm{BMI}$ as independent variables and we obtained an odds ratio of 3.78 (confidence interval 2.77-5.15). Results showed that the likelihood of having co-morbid illnesses was significantly higher among those with COPD for all analysed illnesses, except for heart attack, stroke and malignancies.

In Table 7 the odds ratios for clinical and health status factors for respondents with COPD compared with those without COPD when controlling for age, gender, education and smoking status are presented. Respondents with COPD had a higher likelihood of having all analysed factors compared with respondents without COPD, except frailty. The odds ratio was highest for anaemia and respondents with COPD were three times more likely to be affected by it. In the logistic regression model for obesity, physical activity was included as an independent variable.

\section{DISCUSSION}

\section{Main findings}

The prevalence of COPD in our population was similar to the results obtained in other studies. ${ }^{5}$ Interestingly, we found a relatively high percentage of never-smokers among respondents with COPD. The high prevalence of COPD in those who have never smoked could be explained by the fact that genetic predisposition and exposure other than smoking could be important. ${ }^{7}$ We did not analyse passive smoking, which is also recognised as an important factor contributing to increased risk for COPD in

Table 3. Prevalence of co-morbid illness in respondents with and without COPD according to smoking status

\begin{tabular}{|c|c|c|c|c|c|c|c|c|c|}
\hline \multirow[t]{2}{*}{ Diseases } & \multicolumn{9}{|c|}{ Smoking status } \\
\hline & \multicolumn{3}{|c|}{ Never-smokers } & \multicolumn{3}{|c|}{ Ex-smokers } & \multicolumn{3}{|c|}{ Current smokers } \\
\hline Total N & 3,797 & 206 & & 1,222 & 110 & & 2,486 & 171 & \\
\hline Heart attack & $190(5.0)$ & $11(5.3)$ & 0.83 & $101(8.3)$ & $11(10.1)$ & 0.51 & $111(4.5)$ & $10(5.8)$ & 0.40 \\
\hline Asthma & $97(2.6)$ & $62(30.1)$ & $<0.01$ & $39(3.2)$ & $26(23.6)$ & $<0.01$ & $50(2.0)$ & $37(21.6)$ & $<0.01$ \\
\hline Malignancy & $89(2.3)$ & $9(4.4)$ & 0.07 & $33(2.7)$ & $5(4.5)$ & 0.27 & 46 (1.9) & $4(2.3)$ & 0.65 \\
\hline Diabetes mellitus & 359 (9.5) & $41(19.9)$ & $<0.01$ & $125(10.2)$ & $14(12.7)$ & 0.41 & 139 (5.6) & $19(11.1)$ & $<0.01$ \\
\hline Dyslipidaemia & $613(16.2)$ & $55(26.7)$ & $<0.01$ & 209 (17.1) & $33(30.0)$ & $<0.01$ & $312(12.6)$ & $38(22.1)$ & $<0.01$ \\
\hline Anxiety/depression & $179(4.7)$ & $30(14.6)$ & $<0.01$ & $55(4.5)$ & $17(15.6)$ & $<0.01$ & $121(4.9)$ & 32 (18.6) & $<0.01$ \\
\hline Chronic renal disease & $383(10.1)$ & $41(19.9)$ & $<0.01$ & $119(9.7)$ & $20(18.2)$ & $<0.01$ & $194(7.8)$ & $27(15.8)$ & $<0.01$ \\
\hline Peptic ulcer & $220(5.8)$ & $18(8.8)$ & 0.08 & $121(9.9)$ & $13(11.8)$ & 0.52 & $235(9.5)$ & $37(21.5)$ & $<0.01$ \\
\hline
\end{tabular}


never-smokers. ${ }^{8}$ Hypertension is the most prevalent co-morbidity in our respondents with COPD and is significantly higher among those with COPD compared with respondents without, even when stratified for age group and smoking status. We did not find a statistically significant difference in the prevalence of heart attack between respondents with and without COPD, even when smokers, ex-smokers and non-smokers were separately analysed. This finding could indicate that smoking is an independent risk factor for both COPD and heart attack, and that COPD itself does not increase the risk for heart attack. This was confirmed in a logistic regression analysis, which showed that the presence of COPD was not significant for the occurrence of a heart attack. The prevalence of stroke was not significantly different between respondents with and without COPD when age groups were analysed separately. On the other hand, among never-smokers the prevalence of stroke was similar in respondents with and without COPD. However, among smokers there was a significantly higher prevalence of stroke among those with COPD. After hypertension, the most prevalent co-morbidity in respondents with COPD was dyslipidaemia, which was significantly higher than among respondents without COPD even when stratified for age and smoking status. The prevalence of asthma was 10 times higher in respondents with COPD. The difference was significant even when analysis was performed separately by smoking status. Among functional limitations the most prevalent were visual and mobility impairments. Visual impairment was prevalent in respondents without COPD. The prevalence of mobility impairment was two times higher in respondents with COPD, and the difference was even higher in the younger age group.

\section{Strengths and limitations of this study}

Our study was based on a cross-sectional design that does not allow conclusions to be drawn regarding cause-effect relations. As health survey data were used, spirometry data were not available and thus we were not able to analyse in the context of severity of COPD. The limitations of our study are related to measurement bias because diagnoses of chronic bronchitis or emphysema and lifestyle behaviours were reported by the respondent. Selfreported diagnosis of chronic bronchitis or emphysema could underestimate the prevalence of the disease because mild and moderate stages could be undiagnosed.

Also, data about co-morbidities were self-reported. However, some studies have demonstrated that self-reported data about disease could be considered valid. ${ }^{9,10}$

We are aware that some respondents with more severe symptoms of COPD were more likely to be diagnosed with COPD. On the other hand, those with mild symptoms could be undiagnosed by a physician and so would not be included in our study. We recognise that there is a proportion of respondents who were diagnosed with COPD but would probably not meet the spirometry criteria for COPD, and that some respondents who were not diagnosed by physicians would probably meet spirometry criteria. However, performing spirometry on such a large population sample was not feasible, and we believe that results on a representative population sample using self-reported data could be relevant.

The prevalence of self-reported diseases depends on the true prevalence of the diseases as well as the ability and knowledge of health-care providers diagnosing the disease. The threshold for seeking medical care also varies between population groups (according to gender, age, ethnicity and education level). Individuals with symptomatic chronic disease would visit healthcare providers more often compared with individuals with minor or no symptomatic diseases. This would probably increase the differences in the prevalence of co-morbidities.

For frailty, we have used the modification of Fried's original definition of frailty by including only three out of four criteria. That 
Table 5. Clinical factors and health status factors of respondents according to smoking status

\begin{tabular}{|c|c|c|c|c|c|c|c|c|c|}
\hline \multirow{3}{*}{$\begin{array}{l}\text { Clinical factors and } \\
\text { health status factors }\end{array}$} & \multicolumn{9}{|c|}{ Smoking status } \\
\hline & \multicolumn{3}{|c|}{ Never-smokers } & \multicolumn{3}{|c|}{ Ex-smokers } & \multicolumn{3}{|c|}{ Current smokers } \\
\hline & $\begin{array}{l}\text { Non-COPD, } \\
\mathrm{N}(\%)\end{array}$ & $\begin{array}{l}\text { COPD, } \\
\mathrm{N}(\%)\end{array}$ & $P$ & $\begin{array}{l}\text { Non-COPD, } \\
\mathrm{N}(\%)\end{array}$ & $\begin{array}{l}C O P D, \\
\mathrm{~N}(\%)\end{array}$ & $P$ & $\begin{array}{l}\text { Non-COPD, } \\
\mathrm{N}(\%)\end{array}$ & $\begin{array}{l}C O P D, \\
\mathrm{~N}(\%)\end{array}$ & $P$ \\
\hline \multicolumn{10}{|l|}{ Clinical factors } \\
\hline Dizziness & $502(13.2)$ & $51(24.8)$ & $<0.01$ & $135(11.1)$ & $22(19.8)$ & $<0.01$ & $289(11.7)$ & $47(28.0)$ & $<0.01$ \\
\hline Obesity & $934(25.3)$ & $68(34.2)$ & $<0.01$ & $321(26.8)$ & $31(29.5)$ & 0.55 & 445 (18.2) & $39(22.8)$ & 0.13 \\
\hline Anaemia & $153(4.0)$ & $17(8.3)$ & $<0.01$ & $40(3.3)$ & $9(8.2)$ & $<0.01$ & $71(2.9)$ & $26(15.2)$ & $<0.01$ \\
\hline Frailty & $38(1.0)$ & $6(3.0)$ & 0.01 & $6(0.5)$ & $1(0.9)$ & 0.55 & $12(0.5)$ & $3(1.8)$ & 0.03 \\
\hline \multicolumn{10}{|l|}{ Health status factors } \\
\hline Mobility difficulty & $595(15.8)$ & $68(33.0)$ & $<0.01$ & $173(14.2)$ & $36(32.7)$ & $<0.01$ & $196(7.9)$ & $44(25.7)$ & $<0.01$ \\
\hline Hearing impairment & $293(7.7)$ & $30(14.6)$ & $<0.01$ & $82(6.7)$ & $15(13.6)$ & $<0.01$ & $113(4.6)$ & $16(9.4)$ & $<0.01$ \\
\hline Visual impairment & 439 (11.6) & $45(21.8)$ & $<0.01$ & $139(11.4)$ & $22(19.8)$ & $<0.01$ & $180(7.3)$ & $28(16.3)$ & $<0.01$ \\
\hline
\end{tabular}

Table 6. Logistic regression models of co-morbid illness adjusted for age, gender, education level and smoking status

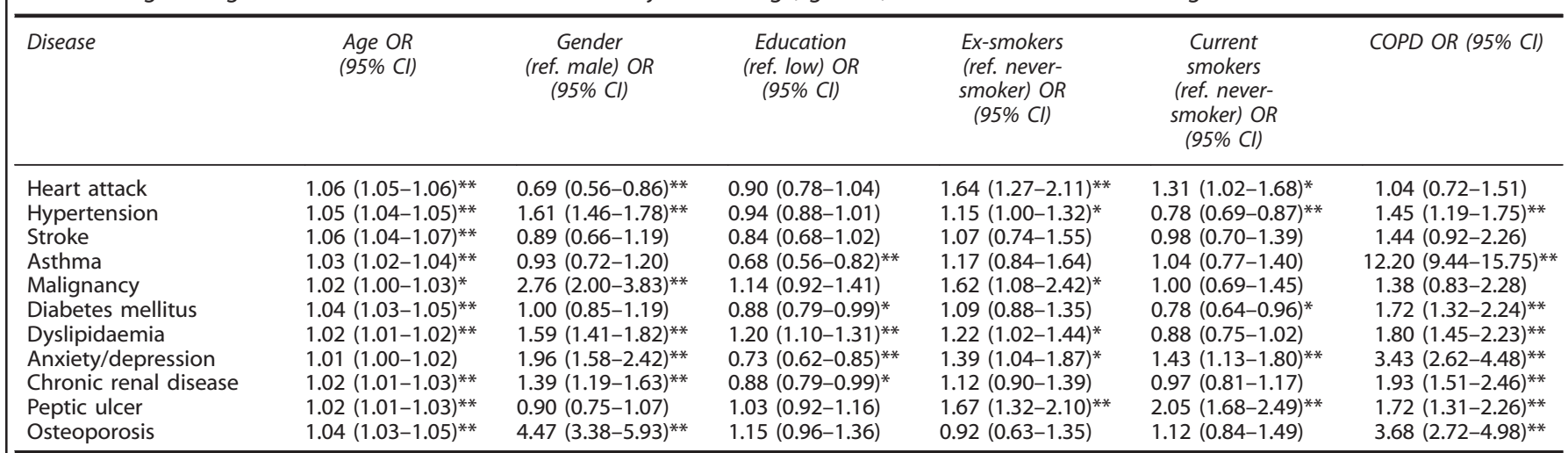

Abbreviations: $\mathrm{Cl}$, confidence interval; $\mathrm{COPD}$, chronic obstructive pulmonary disease; OR, odds ratio; ref., reference.

${ }^{*} P<0.05 ;{ }^{*} P<0.01$

Table 7. Logistic regression models for clinical factors and health status factors adjusted for age, gender, education level and smoking status

\begin{tabular}{|c|c|c|c|c|c|c|}
\hline & Age OR $(95 \% \mathrm{Cl})$ & $\begin{array}{c}\text { Gender (ref. male) } \\
\text { OR }(95 \% \mathrm{Cl})\end{array}$ & $\begin{array}{c}\text { Education (ref. low) } \\
\text { OR }(95 \% \mathrm{Cl})\end{array}$ & $\begin{array}{l}\text { Ex-smokers (ref. never- } \\
\text { smokers) OR }(95 \% \mathrm{Cl})\end{array}$ & $\begin{array}{l}\text { Current smokers } \\
\text { (ref. never-smokers) } \\
\text { OR }(95 \% \text { Cl) }\end{array}$ & COPD OR $(95 \% \mathrm{Cl})$ \\
\hline Dizziness & $1.02(1.01-1.03)^{* *}$ & $2.33(2.02-2.69)^{* *}$ & $0.71(0.64-0.79)^{* * *}$ & $1.24(1.01-1.52)^{*}$ & $1.35(1.15-1.59)^{* *}$ & $2.01(1.61-2.51)^{* *}$ \\
\hline Obesity $^{\mathrm{a}}$ & $0.99(0.99-0.99)^{*}$ & $1.28(1.15-1.44)^{* * *}$ & $0.78(0.72-0.85)^{* * *}$ & $1.24(1.06-1.43)^{* * *}$ & $0.68(0.60-0.78)^{* *}$ & $1.28(1.04-1.58)^{*}$ \\
\hline Anaemia & $1.00(0.99-1.01)$ & $6.56(4.83-8.91)^{* *}$ & $1.24(1.05-1.47)^{*}$ & 1.39 (0.98-1.97) & $1.04(0.79-1.38)$ & $2.99(2.16-4.13)^{* *}$ \\
\hline Frailty & $1.12(1.09-1.14)^{* *}$ & $3.36(1.92-5.88)^{* *}$ & $0.75(0.50-1.13)$ & $0.96(0.42-2.21)$ & $1.68(0.88-3.20)$ & $1.73(0.86-3.50)$ \\
\hline $\begin{array}{l}\text { Mobility } \\
\text { difficulty }\end{array}$ & $1.10(1.09-1.10)^{* *}$ & $2.01(1.72-2.35)^{* *}$ & $0.54(0.48-0.60)^{* *}$ & $1.48(1.21-1.81)^{* * *}$ & $1.28(1.07-1.54)^{* *}$ & $2.35(1.87-2.96)^{* *}$ \\
\hline $\begin{array}{l}\text { Hearing } \\
\text { impairment }\end{array}$ & $1.10(1.09-1.11)^{* *}$ & $0.80(0.66-0.98)^{*}$ & $0.64(0.56-0.74)^{* *}$ & $0.96(0.74-1.25)$ & $1.26(0.99-1.60)$ & $1.62(1.20-2.18)^{* *}$ \\
\hline $\begin{array}{l}\text { Visual } \\
\text { impairment }\end{array}$ & $1.06(1.05-1.07)^{* *}$ & $1.40(1.19-1.64)^{* * *}$ & $0.71(0.63-0.79)^{* *}$ & $1.26(1.03-1.56)^{*}$ & $1.13(0.94-1.37)$ & $1.65(1.29-2.11)^{* *}$ \\
\hline
\end{tabular}


could possibly explain the rather small percentage of respondents classified as frail.

Interpretation of findings in relation to previously published work The prevalence of hypertension in respondents with COPD is similar to the results obtained by Schnell et al.; ${ }^{6}$ however, the prevalence was two times higher than that reported by Van Manenen et al. ${ }^{9}$ The explanation for such a high prevalence is that hypertension is highly prevalent in the general population in Serbia, and $40.6 \%$ of respondents without COPD reported having hypertension.

Taking into account other studies with different results-some showing that COPD is an independent risk factor for ischaemic heart disease ${ }^{11}$ and others finding a lower risk for ischaemic heart disease among subjects with COPD $^{12}$ - further investigation is necessary. As our study was based on self-reported COPD, we did not have data regarding the stage of disease. Respondents with more severe stage of disease could have hypoxaemia due to chronic obstructive disease, which could influence coronary circulation and lead to a heart attack. Systemic inflammation is an extrapulmonary manifestation of COPD. A possible connection between COPD and the appearance of cardiovascular comorbidities can be the presence of specific inflammatory cells in the formation of atherosclerotic plaques, plaque rupture and atherothrombosis. $^{13}$

Smoking habits can be a risk for lung and systemic inflammation, oxidative stress and changes in vasomotor circulation. ${ }^{12}$

The PLATINO study found a significantly higher prevalence of asthma in respondents with COPD. ${ }^{14}$ Our results showed that the likelihood of being diagnosed with asthma was 12 times higher for respondents with COPD even when adjusting for age, gender, smoking status and education level. COPD is often misdiagnosed as asthma, leading to inappropriate treatment and suboptimal patient outcomes. ${ }^{15}$

Romme et al. found that the prevalence of osteoporosis is high in patients with COPD and we obtained similar results. Risk factors contributing to osteoporosis in COPD could be long corticosteroid therapy, overweight and old age of subjects. ${ }^{16}$

The prevalence of depression and anxiety in COPD was in the range of $7-80 \%$ in different studies. ${ }^{17-19}$ In our study, subjects with COPD were three times more likely to have anxiety or depression compared with those without COPD. Theorems relating to depression in COPD have focussed on the mechanisms associated with the complicated role of smoking, hypoxia, systemic inflammation and the impact of illness on patients' lives.

Besides co-morbidities, some functional limitations such as cognitive impairment and limited mobility could be present in patients with COPD and affect patients' adhering to treatment. ${ }^{6}$

Implications for further research, policy and practice

In respondents with COPD, we found a significant prevalence of co-morbidities that can significantly influence the treatment and prognosis of COPD. However, it has been found that comorbidities could be undetected and therefore not taken into account during the treatment of COPD. ${ }^{20}$ The finding suggests that health-care workers should actively assess co-morbidities in patients with COPD. Guidelines for management of COPD should focus on the most prevalent co-morbidities in order to enhance effective management of COPD. Development of a simple test that could be used to detect the possible presence of co-morbidities would be important for the management of COPD. An example of a simple test is the COPD Assessment Test questionnaire, which can also be used as a useful tool for assessing patients' experience of COPD. COPD Assessment Test proved to be a practical tool for assisting primary care physicians in the identification of patients at increased risk for exacerbations. ${ }^{21}$

\section{Conclusion}

Our analysis showed that the most prevalent co-morbidities in respondents with COPD were hypertension, dyslipidaemia, chronic renal disease and anxiety/depression. For management of COPD it is very important to take into account co-morbidities and functional limitations.

\section{ACKNOWLEDGEMENTS}

The authors acknowledge the Ministry of Health of the Republic of Serbia, because the study is a part of the 'Health Survey of the Population of Serbia' funded by the Ministry of Health of the Republic of Serbia. Data were obtained from the National Health Survey with agreement of the Ministry of Health of the Republic of Serbia.

\section{CONTRIBUTIONS}

LMN-O designed the study, prepared the draft, revised it and wrote the final version. DSV participated in designing the study, analysed the data and participated in drafting and revising the paper.

\section{COMPETING INTERESTS}

The authors declare no conflict of interests.

\section{FUNDING}

This study was funded by the Ministry of Education and Science of the Republic of Serbia through project Nos. 175081 and 175042.

\section{REFERENCES}

1 Government of Serbia. Second progress report on the implementation of the poverty reduction strategy in Serbia, 2007 [in Serbian]. http://www.prsp.sr.gov.rs. 2 National WHOHealth accounts. http://www.who.int/nha/country/SCG.pdf.

3 Winkler A. Measuring regional inequality: an index of socio-economic pressure for Serbia. Collection of Papers-Faculty of Geography at University of Belgrade 2012; 60: 81-102.

4 Nielsen R, Johannessen A, Benediktsdottir B, Gislason T, Buist AS, Gulsvik A et al. Present and future costs of COPD in Iceland and Norway: results from BOLD study. Eur Respir J 2009; 34: 850-857.

5 Aryal S, Diaz-Guzman E, Mannino DM. Prevalence of COPD and comorbidity. In: Rabe KF, Wedzica JA, Wouters EFM (eds). COPD and Comorbidity. European Respiratory Monograph, vol 59. European Respiratory Society: Sheffield, UK, 2013: $1-12$.

6 Schnell K, Oweiss C, Lee T, Krishnan JA, Leff B, Wolf JL et al. The prevalence of clinically-relevant comorbid conditions in patients with physician-diagnosed COPD: a cross-sectional study using data from NHANES 1999-2008. BMC Pulm Med 2012; 12: 26.

7 Buist AS, McBurnie MA, Vollmer RM, Gillespie S, Burney P, Mannino DM et al. International variation in the prevalence of COPD (The BOLD Study): a populationbased prevalence study. Lancet 2007; 370: 741-750.

8 Hagstad S, Bjerg A, Ekerljung L, Backman H, Lindberg A, Roenmark E et al. Passive smoking exposure is associated with increased risk of COPD in never smokers. Chest 2014; 145: 1298-1304.

9 van Manen JG, Bindels PJ, Dekker EW, ljzermans CJ, Bottema BJ, van der Zee JS et al. Prevalence of comorbidity in patients with chronic airway obstruction and controls over the age of 40. J Clin Epidemiol 2001; 54: 287-293.

10 Barr RG, Herbstman J, Speizer FE, Camargo CA. Validation of self-reported chronic obstructive pulmonary disease in a cohort study of nurses. Am J Epidemiol 2002; 155: 965-971.

11 Agusti A, Calverley PMA, Celli B, Coxson HO, Edwards LD, Lomas DA et al. Characterisation of COPD heterogeneity in the ECLIPSE cohort. Respir Res 2010; 11: 122.

12 Joo H, Park J, Do Lee S, Oh Y. Comorbidities of chronic obstructive pulmonary disease in Koreans: a population-based study. J Korean Med Sci 2012; 27: 901-906.

13 Maclay JD, NacNee W. Assessment of cardiovascular comorbidity. In: Rabe KF, Wedzica JA, Wouters EFM (eds). COPD and Comorbidity. European Respiratory Monograph, vol 59. European Respiratory Society: Sheffield, UK, 2013: 28-49.

14 Lopez Varela MV, Montes de Oca M, Halbert R, Muino A, Talamo C, Prez-Padilla R et al. Comorbidities and health status in individuals with and without COPD in five Latin American cities: the PLATINO study. Arch Bronconeumol 2013; 49: 468-474. 
15 Tinkelman DG, Price DB, Nordyke RJ, Halbert RJ. Misdiagnosis of COPD and asthma in primary care patients 40 years of age and over. $J$ Asthma 2006; 43 : 75-80.

16 Romme EA, Smeenk FW, Wouters EF, Rutten EP. Osteoporosis in COPD. In: Rabe KF, Wedzica JA, Wouters EFM (eds). COPD and Comorbidity. European Respiratory Monograph, vol 59. European Respiratory Society: Sheffield, UK, 2013 93-104.

17 Cafarella PA, Effing TW, Barton C, Ahmed D, Frith PA. Management of depression and anxiety in COPD. In: Rabe KF, Wedzica JA, Wouters EFM (eds). COPD and Comorbidity. European Respiratory Monograph, vol 59. European Respiratory Society: Sheffield, UK, 2013: 144-163.

18 Hynninen MJ, Breitve MH, Wiborg AB. Psychological characteristics of patients with chronic obstructive pulmonary disease: a review. J Psychosom Res 2005; 59 429-443.

19 Yohannes AM, Willgoss TG, Baldwin RC. Depression and anxiety in chronic heart failure and chronic obstructive pulmonary disease: prevalence, relevance,

clinical implications and management principles. Int J Geriatr Psych 2010; 25 1209-1221.

20 Garvey C. Depression in patients with chronic obstructive pulmonary disease. Postgrad Med 2012; 124: 101-109.

21 Gruffydd-Jones K, Marsden HC, Holmes S, Kardos P, Escamilla R, Dal Negro R et al Utility of COPD Assessment Test (CAT) in primary care consultations: a randomised controlled trial. Prim Care Respir J 2013; 22: 37-43.

(i) This work is licensed under a Creative Commons Attribution 4.0 International License. The images or other third party material in this article are included in the article's Creative Commons license, unless indicated otherwise in the credit line; if the material is not included under the Creative Commons license, users will need to obtain permission from the license holder to reproduce the material. To view a copy of this license, visit http://creativecommons.org/ licenses/by/4.0/ 